\title{
Comparison of Simultaneous Chatanika and Millstone Hill Observations With Ionospheric Model Predictions
}

\author{
C. E. Rasmussen, ' R. W. Schunk, ${ }^{1}$ J. J. Sojka, ${ }^{2}$ V. B. Wickwar, ${ }^{2}$ O. De la Beaujardiere, ${ }^{2}$ \\ J. Foster, ${ }^{3}$ J. HOLT, ${ }^{3}$ D. S. Evans, ${ }^{4}$ AND E. NIELSEN ${ }^{5}$
}

\begin{abstract}
As part of the MITHRAS program, the Chatanika and Millstone Hill incoherent-scatter radars made coordinated observations of the polar ionosphere on June 27 and 28, 1981. We compare these data with predictions made by a high-latitude ionospheric model. Qualitatively, the same features are evident in both the model and the radar data: fairly constant densities on the dayside with a mid-latitude trough forming poleward of 65 degrees around $1900 \mathrm{MLT}$ (magnetic local time). This trough is seen to extend equatorward with increasing MLT, such that the minimum densities occurring in the trough appear just after midnight around 60 degrees dipole latitude. These features are primarily understood in terms of different regions of convection, further influenced by photoionization and vertical transport. The only areas of major disagreement between the measurements and model are noted in the auroral oval and at a portion of the times during which substorms occurred. Quantitatively, equally good agreement is obtained between the model predictions and the radar data. The densities predicted by the model are usually within $25 \%$ of those measured by the radars, alth ough a ppreciable differences occur in some regions of the ionosphere at certain times.
\end{abstract}

\section{INTRODUCTION}

Over the past several years we have developed a comprehensive model of the convecting high-latitude ionosphere [cf. Schunk and Raitt, 1980; Sojka et al., 1981a, b, c, 1982a, b; Schunk and Sojka, 1982a, $b$ ]. This model allows us to obtain a better understanding of the manner in which various chemical and transport processes affect the ion composition and electron density at $F$ region altitudes. For instance, one of the important results that has emerged from these studies is that high-latitude ionospheric features, such as the "main trough," the "ionization hole," the "tongue of ionization," and the "aurorally produced ionization peaks," are a natural consequence of the competition between the various chemical and transport processes known to be operating in the high-latitude ionosphere.

An important part of the development of the model has been the comparison of model predictions with observations. For instance, we have compared the plasma convection patterns, which are an input to our numerical model, with those observed concurrently at Chatanika, Alaska, and Millstone Hill, Massachusetts [Sojka et al., 1980]. We have also compared the electron density and ion compostional variations obtained from our model [Sojka et al., 1981a, b] with the Atmosphere Explorer (AE-C) satellite data presented by Brinton et al. [1978]. Another study used ion density measurements from the Defense Meteorological Satellite Program (DMSP) F2 and F4 satellites to exa mine the UT dependence of the high-latitude ion density at $800 \mathrm{~km}$ [Sojka et al., 1982b]. In general, good quantitative agreement was obtained between theory and measurements in these studies, although the comparisons were hindered somewhat in that the experimental data were either averaged over several days or were limited to data obtained only along individual satellite tracks. Therefore, it becomes important to

\footnotetext{
'Utah State University, Logan.

${ }^{2}$ SRI International, Menlo Park, California.

${ }^{3}$ MIT Haystack Observatory, Westford, Massachusetts.

${ }^{4}$ National Center for Atmospheric Research, Boulder, Colorado.

${ }^{5}$ Max Planck Institute, Lindau, Federal Republic of Germany.

Copyright 1986 by the American Geophysical Union.
}

Paper number 5A8540.

0148-0227/86/005A-8540\$05.00 compare the model with a more comprehensive, experimental data base.

Between May 1981 and June 1982, an intensive campaign of 33 coordinated observations was carried out using three incoherent-scatter radars: Chatanika (Alaska); Millstone Hill (Massachusetts); and European Incoherent Scatter (EISCAT) (Scandinavia) [de la Beaujardiere et al., 1984]. At times the Scandinavian Twin Auroral Radar Experiment (STARE) radar (Scandinavia) was able to provide additional coverage. This experimental campaign has become known as the Magnetosphere-Ionosphere-Thermosphere Radar Studies (MITHRAS) program, and the data base obtained from the campaign provides an excellent opportunity for a comparison of the high-latitude model with observations.

Sojka et al. [1983] have made an initial comparison of the model with a portion of the MITHRAS data which covered a 24-hour period beginning on October 13, 1979. As the model required several input parameters (to be discussed later), this study compared the model densities with Millstone Hill data for a range of input conditions at an altitude of $500 \mathrm{~km}$. The model predicted quite well the experimental data, except in the region of the auroral oval where enhanced auroral precipitation occurred.

One limitation of the above study was in not having enough data to adequately infer the information needed as inputs to the high-latitude model. A major emphasis in this study is placed upon matching, as closely as possible, the required inputs to the model with data obtained from the radars, including STARE. Another required input, pertaining to the location and extent of auroral precipitation, was acquired from data obtained by the NOAA 6 satellite. A further limitation of the above study was that the comparison was made with data from only one radar and at only one altitude. In the present paper, we compare the model with electron density measurements made by the Chatanika and Millstone Hill radars at two altitudes. We also compare the variation in the altitude dependence of the electron density as the Chatanika radar moves in local time. The data obtained for this study were taken on June 27 and 28, 1981.

The predictions of the model are compared with experimental data taken by radars in the reference frame of the respective radar, i.e., as an observer at a fixed location on the earth's surface moves in local time. A comparison of the predictions of 
the model with experimental data-in the reference frame of the radars-allows for validation of the input parameters selected ior use in the model run. Once this is established, the data base reated by the model can be examined in reference frames that the radars cannot view. For instance, it is shown that a "snapshot" of the polar ionosphere at a given UT can a ppear substantially different from the data taken by a radar. Also, full latitudinal coverage from $42^{\circ}$ to the pole is obtained by the model and gllows for an accurate extrapolation of the radar data into spatial regions of the ionosphere where the radar coverage cannot reach. This points out one of the most beneficial aspects of the model when used in conjunction with radar data: the ability to "extend" the coverage of the radars into spatial and temporal regions beyond their normal reach.

\section{RADARS}

\subsection{Chatanika}

The data for June 27 to 28, 1981, from Chatanika were acquired in the MITHRAS 1 mode [de la Beaujardiere et al., 1984]. Briefly, this mode was designed to provide an extended set of geophysical parameters over a wide range of invariant latitude with about $30 \mathrm{~min}$ time resolution. The wide range is obtained by using $F$ region measurements - the higher the altitude, the wider the range. As a consequence the experimental setup has been optimized for $F$ region parameters. Nonetheless, some $E$ region parameters are obtained over a small range of invariant latitude.

For this study the $F$ region parameters of interest include vector ion velocities, electron densities, electron and ion temperatures, and neutral wind in the magnetic meridian. The $E$ region parameter of interest is the energy deposition by precipitating auroral particles. The ion velocities are found between $60^{\circ}$ and $72^{\circ} \Lambda$, with a small gap in the middle corresponding to the radar location. The electron density and temperature are found over an invariant-latitude range, which is determined by the altitude, that is somewhat more restricted than for ion velocity. The meridional wind is found for the field line passing through the radar, i.e., at $64^{\circ} \Lambda$. The height-integrated particle energy deposition is found between $63.3^{\circ}$ and $66.9^{\circ} \Lambda$. (The invariant latitudes are derived from the International Geomagnetic Reference Field (IGRF) 1980 model [IAGA, 1981] updated to 1981.)

More specifically, the radar was operated with the antenna pointing in a sequence of 11 positions [Foster et al., 1981]: five pairs straddling the magnetic meridian plane at $29^{\circ}$ geographic azimuth and one position parallel to the magnetic field (Table 1). Therefore, measurements from the same altitude in a pair of positions are at the same invariant latitude. It also follows that the lowest-altitude measurements are closest to the radar and have the smallest east-west separation. In each position, eight complete spectral measurements (for the derivation of all parameters) were made between 120 and $480 \mathrm{~km}$ altitude, and power measurements ( for $N_{e}$ derivation) were made every $9 \mathrm{~km}$ in range throughout the $E$ and $F$ regions.

After every five of these sets of measurements, the mode changed for $12.5 \mathrm{~min}$. During that time the antenna performed a continuous elevation scan in the magnetic meridian plane from $25^{\circ}$ above the southern horizon to $25^{\circ}$ above the northern horizon. The same set of spectral and power measurements was made.

A $320-\mu$ s pulse length was used for all the measurements,
TABLE 1. Azimuth and Elevation Angles for the 11-Position Mode

\begin{tabular}{ccccc} 
Positions & $\begin{array}{c}\text { Left } \\
\text { Azimuth }\end{array}$ & Elevation & $\begin{array}{c}\text { Right } \\
\text { Azimuth }\end{array}$ & $\begin{array}{c}\text { Integration } \\
\text { Time, s }\end{array}$ \\
\hline 1 and 2 & 14 & 25 & 44 & 180 \\
3 and 4 & -7 & 50 & 65 & 90 \\
5 and 6 & -35 & 70 & 93 & 90 \\
7 & 209 & 76 & $\ldots$ & 90 \\
9 and 8 & -115 & 45 & 173 & 90 \\
10 and 11 & -120 & 25 & 178 & 180 \\
\hline
\end{tabular}

which means that the ionospheric parameters are convolved over $48 \mathrm{~km}$ along the radar line of sight (actually somewhat more for the spectral measurements). This convolution has little effect in the topside $F$ region where the scale lengths for variation are usually much bigger than this. In the $E$ and the bottomside $F$ regions it distorts the density profile, but has little effect on the height-integrated quantity of interest.

For comparison with the model calculations, velocities along the radar line of sight are derived from the Doppler shifts of the eight measurements in the 11 positions. However, for an initial input is is useful to have the vector velocities perpendicular to $\mathbf{B}$. Their derivation has been discussed by Foster et al. [1981] with refinements added for MITHRAS discussed by Wickwar et al. [1984a] and below. To derive them, pairs of measurements are considered at the same altitude on either side of the magnetic meridian plane. The line-of-sight velocities and the magnetic field at each point are used in deriving the vector. If the points are from the three pairs of positions furthest from the magnetic field, then the velocity parallel to the magnetic field contributes little to the line of sight and is ignored in the vector derivation. Otherwise, the velocity measured parallel to $\mathbf{B}$ is included in the derivation.

Thus the derivation of the vectors depends on time constancy of the convection velocities for a proxima tely five minutes and spatial homogeneity over the 150 - to $400-\mathrm{km}$ separation between points at the same invariant latitude. Most of the time these requirements are, indeed, met. These considerations have been discussed most extensively by Jorgensen et al. [1984]. While that discussion pertains specifically to observations at Sondrestrom, it is equally relevant to Chatanika.

The spectral observations and the determination of electron densities and temperatures have been described by Baron [1977] and Kofman and Wickwar [1980]. These parameters are derived from the 11-position measurements at six invariant latitudes: five from the pairs of positions and one along $\mathbf{B}$. To display these data, the east and west values from each pair of positions are averaged together. Because of the small east-west separation, this averaging is reasonable. For purposes of display, the data are interpolated to the desired altitude and then interpolated in invariant latitude.

The neutral wind in the magnetic meridian is derived from observations along $\mathbf{B}$. Basically, the component of ion velocity parallel to $\mathbf{B}$ is the result of ion-neutral diffusion and the effect of neutrals colliding with ions. Because ions are constrained to move along the magnetic field, neutrals moving southward cause ions to move up the magnetic field line. Thus, when it can be assumed that the field lines are equipotentials and that no vertical winds exist, then the neutral wind in the magnetic meridian can be determined. The detailed derivation is given by Wickwar et al. [1984b]. A smoothed approximation to the 
derived wind is used as an input parameter to the model calculations.

Turning to the energy deposition by auroral particles in the $E$ region, the electron densities between 90 and $180 \mathrm{~km}$ are used to derive that parameter. For this calculation, densities from the elevation scans are used. The profiles from along the radar line of sight are transformed to profiles along the magnetic field. They are then converted to energy deposition as described by Wickwar et al.[1975] by using the effective recombination rate and $35 \mathrm{eV}$ per electron-pair created. Since Wickwaret al.[1975], the major change in the procedure has been a small one in the effective recombination rate. While the profile of energy deposition is distorted because of the long transmitted pulse, the height-integrated quantity is little affected.

During the nighttime, the resultant value is the heightintegrated energy input from energetic particles. During the daytime, most of June $27-28,1981$, the resultant value is a combination of the above and a second contribution from the solar-induced ionization. This latter contribution varies smoothly in latitude and time, while the particle contribution does not. Therefore, the two contributions can be separated.

The height-integrated particle input is used to supplement and confirm the energy inputs obtained from the NOAA satellites. The combined set, in turn, is used to determine the location and width of the a uroral oval, and to normalize the particle precipitation model to the observations.

\subsection{Millstone Hill}

The Millstone Hill measurements were made with the fully steerable 46-m antenna. This antenna was operated in a "scanning" mode, in which it was moved slowly and continuously in azimuth, while the incoherent scatter returns were integrated in the computer and recorded on magnetic tape at regular angle increments. The data acquistion mode utilized on June 27-28, 1981 , differed somewhat from the usual MITHRAS 1 procedure [de la Beaujardiere et al., 1984]. Due to a ntenna upgrading work in progress, the antenna was scanned back and forth in a "windshield wiper" motion. Normally, the antenna was returned rapidly to its start position after the completion of each scan, so that all scans were in the same direction. The main effect on the June 1981 data is a somewhat uneven sampling pattern when the data are displayed versus time and latitude.

During the scans the elevation of the antenna was held constant at $4^{\circ}$. The azimuth was scanned between $177.5^{\circ}$ and $267.5^{\circ}$ at a fixed scan rate of $10 \mathrm{deg} / \mathrm{min}$. The integration time was $30 \mathrm{~s}$. Single $2000-\mu \mathrm{s}$ pulses were employed, with 19 range gates spaced $150 \mathrm{~km}$ apart. The invariant latitude coverage of each scan was $46^{\circ}-64^{\circ}$ at $160 \mathrm{~km}, 42^{\circ}-69^{\circ}$ at $325 \mathrm{~km}$, and $39^{\circ}-72^{\circ}$ at $480 \mathrm{~km}$. The local time coverage of the scans was 2.5 hours at $160 \mathrm{~km}, 3.7$ hours at $325 \mathrm{~km}$, and 4.5 hours at $480 \mathrm{~km}$.

The $F$ region electron density, ion temperature, electron temperature, and line-of-sight ion drift were derived from the measured incoherent scatter spectra. Electric field components were extracted from the radar line-of-sight component of the ion drift by assuming that the electric field may be represented by a quasi-static two-dimensional potential, with the potential assumed constant along geomagnetic field lines [Holt et al., 1984].

\subsection{STARE}

The Scandinavian Twin Auroral Radar Experiment (STARE) operates continuously and makes measurements over a large portion of Scandinavia [Greenwald et al., 1978]. The drift is measured from Doppler backscattered echoes from two stations. However, the echo can only be detected if the electric becomes large, the Doppler velocities reach the electric field and Schlegel, 1983]; the data shown in this paper have [Nielsen corrected for this effect.

\section{MOdEL INPUTS}

There are several para meters that are required as inputs to the high-latitude ionospheric model: e.g., the convection electric field, the thermospheric wind, the auroral-electron energy flux and the electron temperature distribution. Fortunately, max of these input parameters can be measured by the radars, thus allowing a more reliable comparison of predicted and measure ionospheric densities. However, the radar measurements cover a limited latitudinal range, and the various latitudes are probed only at certain times as the radars corotate with the earth. The model, on the other hand, requires the input parameters at all latitudes and longitudes, at all times. Consequently, it is convenient to use empirical models for the various input parameters so that values can be obtained everywhere. Our procedure is to adjust the empirical models so that they agree with the radar data at the appropriate times and places, and then to use the resulting empirical models as the inputs to our high-latitude ionospheric model. A description of these empirical models and a comparison of the model results with the radar data are given in the subsections which follow.

First, a description of the magnetic dipole reference frame, used internally within the model and also to plot much of the data, is given. The magnetic frame is defined by a dipole magnetic field whose pole is located at $78.6^{\circ} \mathrm{N},-69.8^{\circ} \mathrm{E}$ in geographic coordinates. This location is based upon the dipole component of the Mead [1970] magnetic reference field. In this reference frame we use dipole latitude and magnetic local time (MLT) as the magnetic coordinates.

\subsection{Convection Electric Field}

The convection electric field can be obtained from the Volland [Volland, 1978] or Heelis [Heelis et al., 1982] empirical models. Both of these models describe a two-cell convection pattern with antisunward flow over the polar cap and return flow at lower latitudes. The models can be adjusted by varying the cross-tail magnetospheric electric potential, the polar cap radius, the falloff rate outside the polar cap, and the offset of the pattern from the magnetic pole. Also, the convection cells can be asymmetric and the whole pattern can be rotated toward either dawn or dusk.

We considered many different electric field patterns in our attempt to match the line-of-sight velocities measured simultaneously by the Chatanika, Millstone Hill, and STARE radars. One of the problems we faced was that five substorms occurred during the 24-hour period of interest [de la Beaujardiere et al., 1983]. Unfortunately, data from just three radars are not sufficient to determine the electric field variation over the entire high-latitude region during substorms, and hence, we could not model these substorms. Instead, we selected a convection electric field model that best fit the overall variation seen by the radars during the course of the day.

Because of this, our calculated densities and velocities are in a sense average quantities, and one should not expect good agreement between predicted and measured quantities at all 

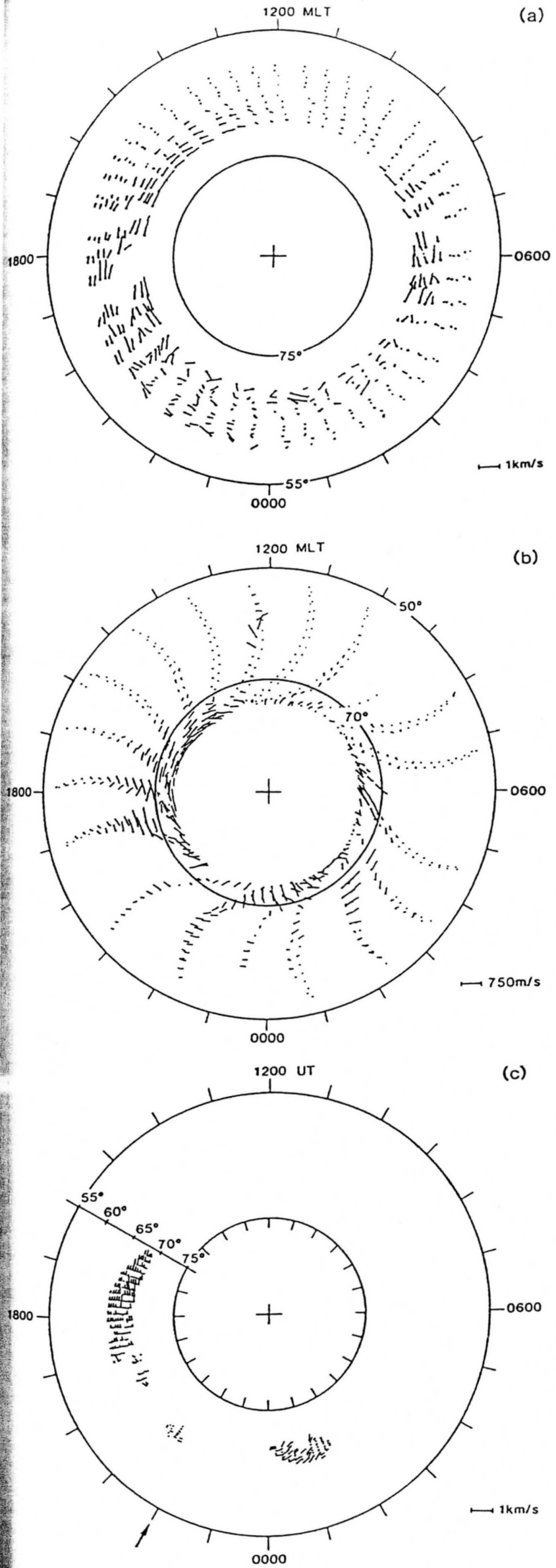

times and places. This limitation should be kept in mind in comparing predicted and measured quantities.

We used velocity data from three radars to obtain a model of ionospheric convection. The data from the Chatanika and Millstone Hill radars are plotted in Figures $1 a$ and $1 b$, respectively, while in Figure $1 c$ the convection data from the STARE radar are shown. The starting times for each of these series of measurements are $0400 \mathrm{UT}$ (1630 MLT), $0340 \mathrm{UT}$ (2100 MLT), and 1600. UT (1800 MLT), respectively. The convection patterns measured by the three radars can be compared with the adopted convection pattern used in our high-latitude model, which is shown in Figure 2. The data in Figure 1 were taken as the radars rotate in local time, and although the convection pattern plotted in Figure 2 represents conditions at a fixed universal time, these figures can be directly compared because the adopted convection pattern is held fixed in time.

The adopted convection pattern is a modified Volland model with a west ward rotation of 1.75 hours. This rotation value was needed to conform to the Chatanika, Millstone Hill, and STARE data in the evening sector, although the rotation is not evident in the Millstone Hill data on the dayside. However, the slight discrepancy between modeled and measured velocities on the dayside should not appreciably affect the densities because the ionosphere is sunlit in this region. The westward rotation used in our model is consistent with measurements of the Millstone Hill radar made throughout the year 1978, when westward rotations of up to two hours were noted [Oliver et al., 1983].

It should be noted that a Heelis convection model could also have fit the data displayed in Figure 1. Without knowledge about plasma flow over the polar cap, there is insufficient information to adequately select which convection model, Volland or Heelis, should be used. Unfortunately, information about polar cap flow was not available, and we rather arbitrarily decided upon a modified Volland model. It is expected that these two convection models would lead to predictions of different plasma densities in some regions of the ionosphere.

Some of the other parameters that define the convection model are the polar cap radius, the value of $K p$ which is used to determine the cross-tail electric potential, and the falloff rate with distance of the electric field outside of the polar cap region. Figure 2 represents the convection model with a $K p$ of 4 , a cross-tail potential of $76 \mathrm{kV}$, a polar cap radius of $17.2^{\circ}$, and a falloff rate of $r^{-4}$ where $r=\sin \left(90^{\circ}\right.$ - latitude $)$ in magnetic dipole coordinates. In comparison, a $\Sigma K p$ of 20- was measured for the days in question. A cross-tail potential of $76 \mathrm{kV}$ is just slightly less than that estimated by de la Beaujardiere et al. [1983] for two of the substorms (starting at 1600, June 27, and 0005, June 18) that occurred during the days under consideration and much less than a third (0430, June 27).

It is not immediately obvious, in comparing Figures 1 and 2, that this is the best model fit. Thus, we present line-of-sight velocities from the Chatanika and Millstone Hill radars for a more quantitative comparison.

Line-of-sight velocities measured by the Millstone Hill radar are plotted in Figure $3 a$. This figure corresponds to measure-

Fig. 1. The convection velocities as measured by the three radars: (a) Chatanika; $(b)$ Millstone Hill; and $(c)$ STARE. The plots are a polar projection with the pole at the center of the diagram and magnetic local time displayed on the outer circle, except in Figure $1 c$ where universal time is displayed with an arrow pointing toward local midnight. The scale for the length of the vectors is given in the lower right-hand corner. 


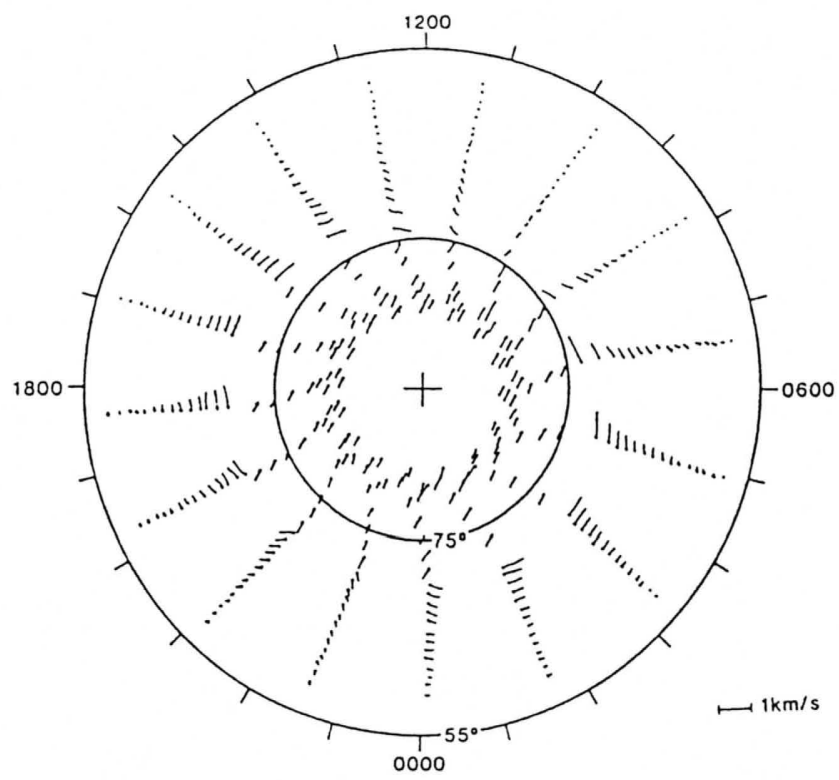

Fig. 2. The Volland convection pattern used in the high-latitude model. The corotation velocity of the plasma has been subtracted so as to correspond with the data in the previous figure. Magnetic local time is displayed on the outer circle while magnetic latitude increases toward the center of the plot. The scale for the length of the vectors is given in the lower right-hand corner.

ments of plasma flow in the reference frame of the radar at $71^{\circ}$ dipole latitude. The solid line shows the line-of-sight velocities that are predicted by our convection model, for the Millstone Hill radar. The peak values in the data (and location in MLT) appear to be well represented by the model, especially considering that the error in the data around 2800 MLT is large and that the predicted velocities would lie within the error bars (if plotted) near this time. It is noted that at times other than near 2800 MLT, the error bars for the line-of-sight velocity data are within the size of the squares representing the data.

The discontinuous nature in the Volland convection model is noted at about 2200 MLT. At this time the model is showing polar cap flow, which is moving in a different direction from the counterstreaming flow that the model had been predicting at earlier times (see Figure 2).

Measurements by the Chatanika radar (corresponding to positions 3 and 4 in Table 1) of the line-of-sight velocities are plotted in Figure $3 b$. The data agree reasonably well with the convection model (which has been plotted as a line) except at the times around 0500 and 1600 hours UT (top scale). These universal times have been identified with periods of substorm activity, with the substorm starting at 0430 UT temporarily increasing the cross-tail potential to nearly $120 \mathrm{kV}$ [de la Beaujardiere et al., 1983]. An increase in the potential d rop across the polar cap (held fixed with time in our model) would increase the line-of-sight velocities at these times, but then agreement would not be found in the other sectors.

Although not shown here, the convection model was also checked against line-of-sight velocities measured by the radars at other latitudes. This was done in order to check the adopted value for the electric field falloff rate. It was found that a value of $r^{-4}$ for the falloff rate is adequate, since the model at different latitudes agrees equally well with the observed velocities.

The selected model for the convection electric field predicts the plasma stream lines shown in Figure 4, where the dots indicate hourly intervals in universal time and the viewpoint is from a quasi-inertial reference frame. Although not all the convection paths are shown in Figure 4, the ones plotted clearly demarcate the differing regions of plasma convection. The plasma near trajectory 1 nearly corotates with the earth, while the plasma near trajectory 2 is virtually stationary for several hours in the evening. Trajectories 4 and 6 outline the dusk and dawn convection cells of counter- and co- rotating plasma, respectively.

As the plasma E X B drifts along the paths shown in Figure 4, the plasma can undergo vertical motion as well, depending upon the dip angle of the magnetic field. The ionospheric density is very sensitive to vertical motion of the plasma, because many of the chemical reactions affecting the electron density depend upon the density of the neutral atmosphere, which varies exponentially with altitude. Contours of the vertical component of the $\mathbf{E} \mathbf{X} \mathbf{B}$ drift are shown in Figure 5 for the convection model selected for this study. This figure shows an upward component of $30 \mathrm{~m} / \mathrm{s}$ on the dayside and a downward component of $45 \mathrm{~m} / \mathrm{s}$ on the nightside.

\subsection{Neutral Wind}

The high-latitude model also requires a knowledge of the neutral wind, which generally blows from day to night across
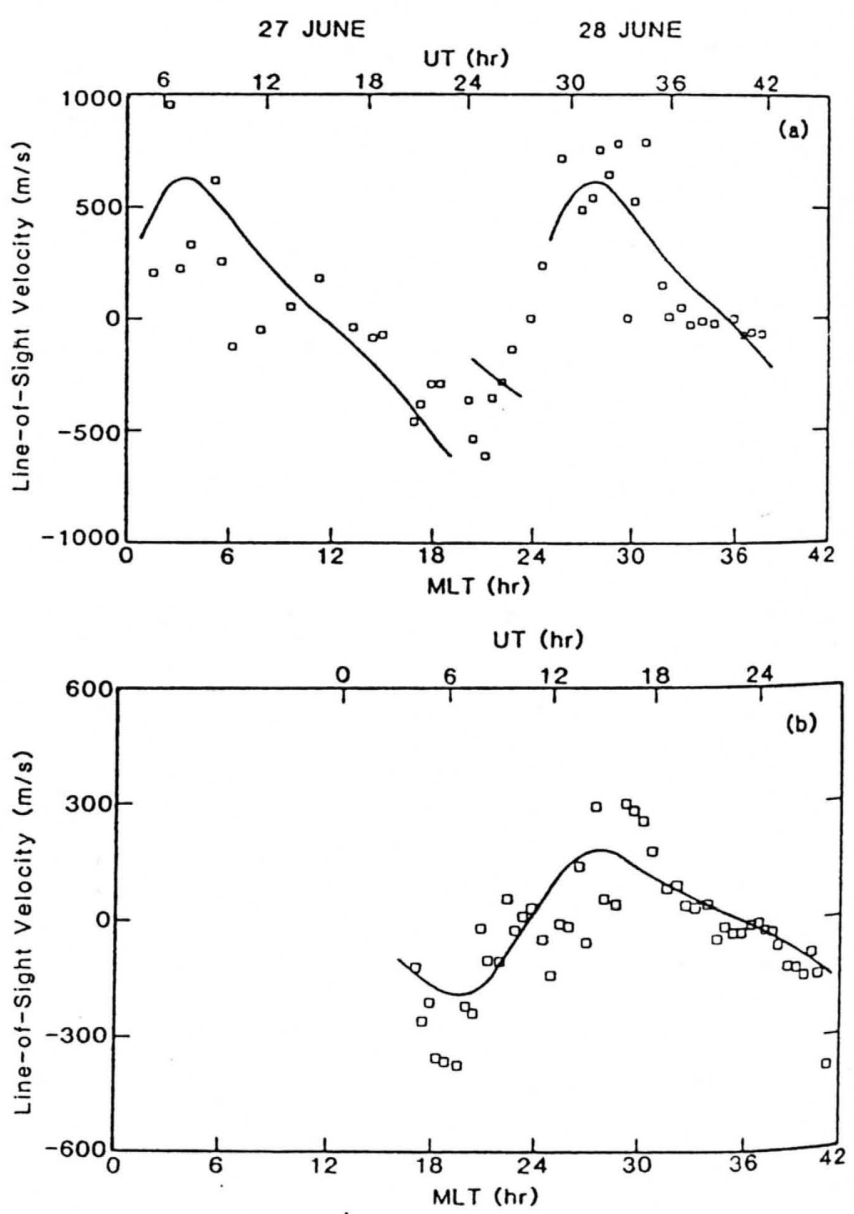

Fig. 3. The line-of-sight convection velocity versus time. Data from the radars are plotted as squares, and the corresponding Volland model result is shown by the solid line. (a) Millstone Hill radar data plotted for radar azimuths between $18^{\circ}$ and $22^{\circ}$ and a range of $2257 \mathrm{~km} .(b)$ Chatanika radar data plotted for a radar azimuth of $65^{\circ}$, elevation of $50^{\circ}$, and a range of $424 \mathrm{~km}$. Most of the data displayed in Figure $3 b$ were taken on June 27. 


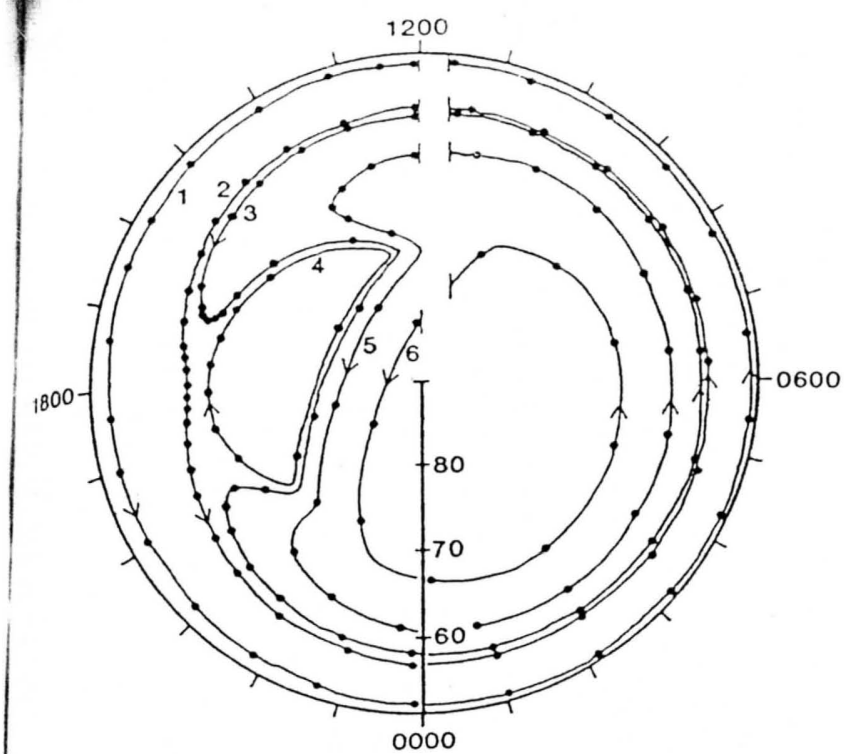

Fig. 4. A schematic diagram of representative paths taken by ionospheric plasma under the influence of corotation and magnetospheric convection, as seen from a quasi-inertial reference frame. Magnetic local time is displayed on the outer circle while magnetic latitude increases toward the center of the plot.

the polar regions. This wind tends to lift the plasma (along magnetic field lines) in the midnight sector and drive the plasma downward in the noon sector. Data were obtained by the Chatanika radar pertaining to the neutral wind (magnetic-meridional component). Although these data varied greatly, the trend seemed to indicate a maximum flow of $200 \mathrm{~m} / \mathrm{s}$ on the nightside and a minimum flow of $30 \mathrm{~m} / \mathrm{s}$ on the dayside, with the wind blowing from 1300 to $0100 \mathrm{LT}$. We assumed the neutral wind to vary smoothly across the terminator, from its dayside to nightside value, between the solar zenith angles of $70^{\circ}$ and $110^{\circ}$. Data pertaining to the zonal wind were not available and, fortunately, were not needed as it is the magnetic-meridional

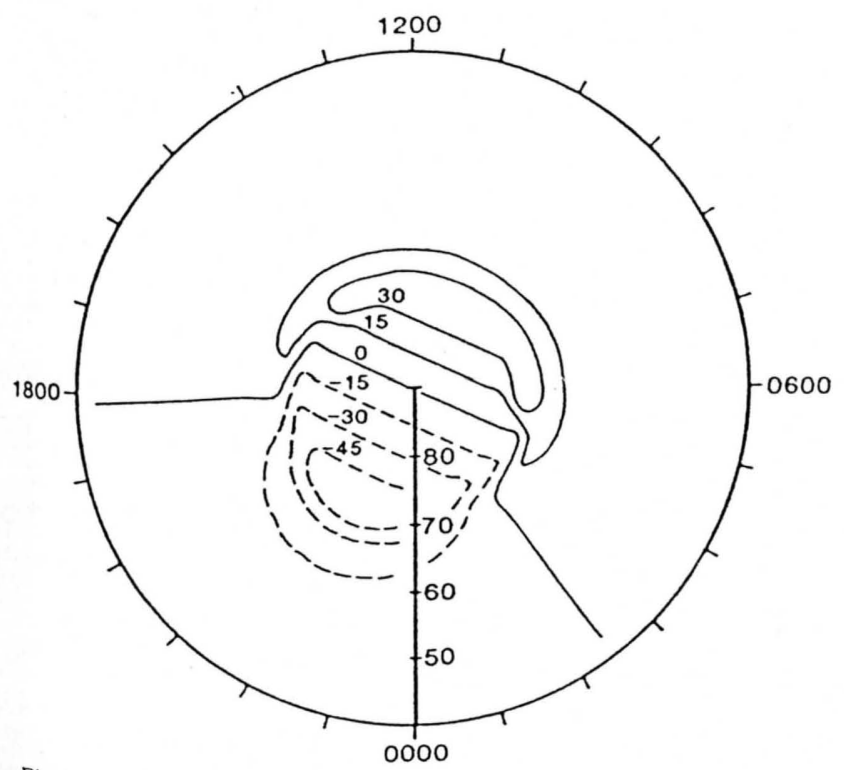

Fig. 5. Contours of the vertical component of the $\mathbf{E} \mathbf{X} \mathbf{B}$ drift used in the high-latitude model. The contour levels are in meters per second. Magnetic dipole latitude is indicated on the radial axis and magnetic local time on the outer circle.

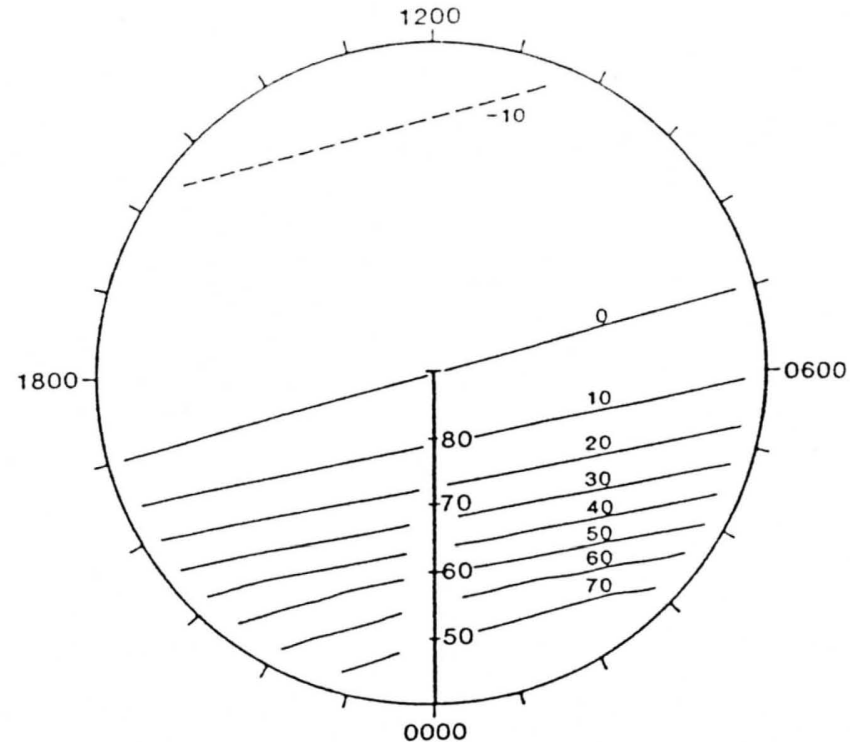

Fig. 6. Contours of the vertical component of the wind-induced ion drift used in the high-latitude model. The contour levels are in meters per second. Magnetic dipole latitude is indicated on the radial axis and magnetic local time on the outer circle.

wind that has a component along the magnetic field lines and is effective in inducing vertical ion drifts. Although a high zonal wind could lead to ion heating and thus affect ion densities, this effect is not presently incorporated in our model.

Contours of the vertical component of the wind-induced ion drift used in the model are shown in Figure 6 at a universal time of 0500 hours. These contours represent a meridional neutral flow of $30 \mathrm{~m} / \mathrm{s}$ on the dayside and $200 \mathrm{~m} / \mathrm{s}$ on the nightside. Figure 6 should be compared with the vertical component of the E X B drift shown in Figure 5, as the plasma density at a given altitude is sensitive to the combined effects of these two ion drifts.

\subsection{Precipitation}

Important input parameters for our ionospheric model are the location and extent of the auroral oval and the magnitude of the ionizing particle precipitation. The particle precipitation model used here is a version of the empirical model of Spiro et al. [1982] which has been modified in light of observations of the actual location of the auroral oval made by the NOAA 6 satellite during the period June 27-28, 1981.

The space environment monitor on the NOAA 6 low-altitude satellite measures the energy flux carried into the atmosphere by precipitating particles (both ions and electrons) of energies between 0.3 and $20.0 \mathrm{keV}$. These energy flux observations directly show the boundary locations, extent, and amount of ionizing radiation over the auroral oval. The line segments in Figure $7 a$ show those portions of northern hemisphere (daytime) NOAA 6 passes that displayed precipitating energy fluxes greater than $1 \mathrm{erg} \mathrm{cm}^{-2} \mathrm{~s}^{-1}$. Similarly, Figure $7 b$ shows those portions of the passes over the southern hemisphere where the energy flux exceeded this threshold. It should be noted that the satellite samples the northern hemisphere over the local daytime hours and the southern over the local nighttime. For the purposes of the modeling we assume the two hemispheres are conjugate in the magnetic local time, magnetic latitude particle 

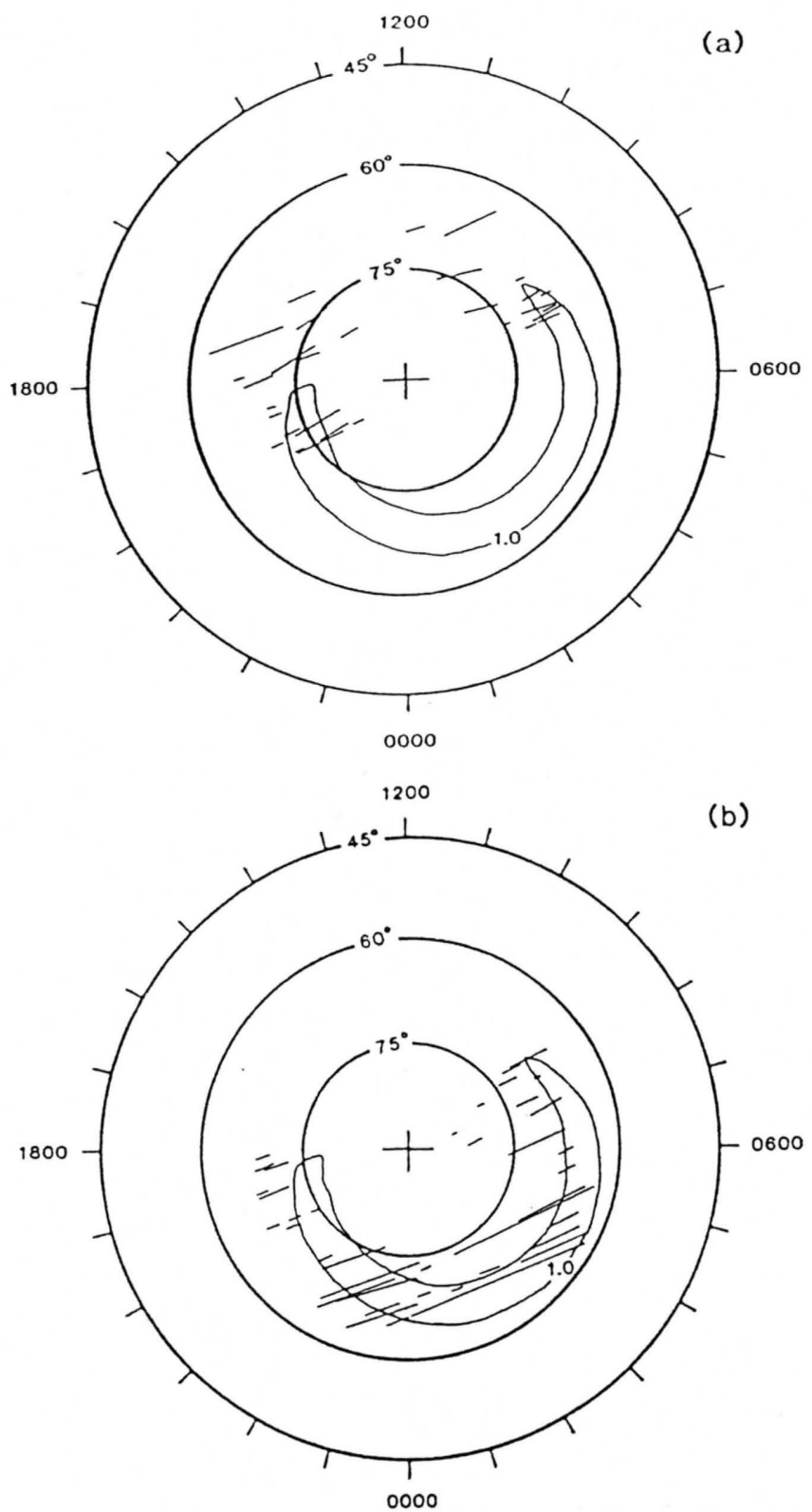

Fig. 7. A contour of electron precipitation at the level of $1 \mathrm{erg} \mathrm{\textrm {cm } ^ { - 2 }}$ $\mathrm{s}^{-1}$, as obtained from the model. Superimposed on the precipitation contour are lines representing the location of the NOAA 6 satellite whenever the measured precipitation was greater than $1 \mathrm{erg} \mathrm{cm}^{-2} \mathrm{~s}^{-1}$ for $(a)$ the northern hemisphere and $(b)$ the southern hemisphere.

precipitation patterns. Because these data were taken over a period of time which contained brief periods of enhanced activity (substorms), the boundaries and extents of the preciptation exhibit considerable variation. However, the simulation was not intended to model these variations, and a single, average precipitation pattern was adopted.

The adopted precipitation model was based upon the $K p 4$ pattern given by Spiro et al. [1982]. This pattern was modified so that the $1 \mathrm{erg} \mathrm{cm}^{-2} \mathrm{~s}^{-1}$ contour better reproduced the average boundary locations shown by the NOAA 6 observations. This modification involved displacing the original Spiro et al. pattern by $2.5^{\circ}$ along the meridian toward $0600 \mathrm{MLT}$ followed by a rotation counterclockwise (toward later MLT) by $30^{\circ}$. The 1 erg $\mathrm{cm}^{-2} \mathrm{~s}^{-1}$ contour for this modified pattern is shown in
Figures $7 a$ and $7 b$ superimposed upon the greater than $1 \mathrm{erg}$ $\mathrm{cm}^{-2} \mathrm{~s}^{-1}$ portions of the NOAA 6 passes. This pattern was adopted for the entire simulation, so that the effects of the substorm enhancements are not taken into account.

Precipitation data obtained by the Chatanika radar were also examined. The radar's latitudinal range was limited and, hence, it was difficult to determine the exact location of the auroral oval from the radar observations alone. However, the radar data were consistent with the NOAA 6 observations whenever direct comparisons could be made.
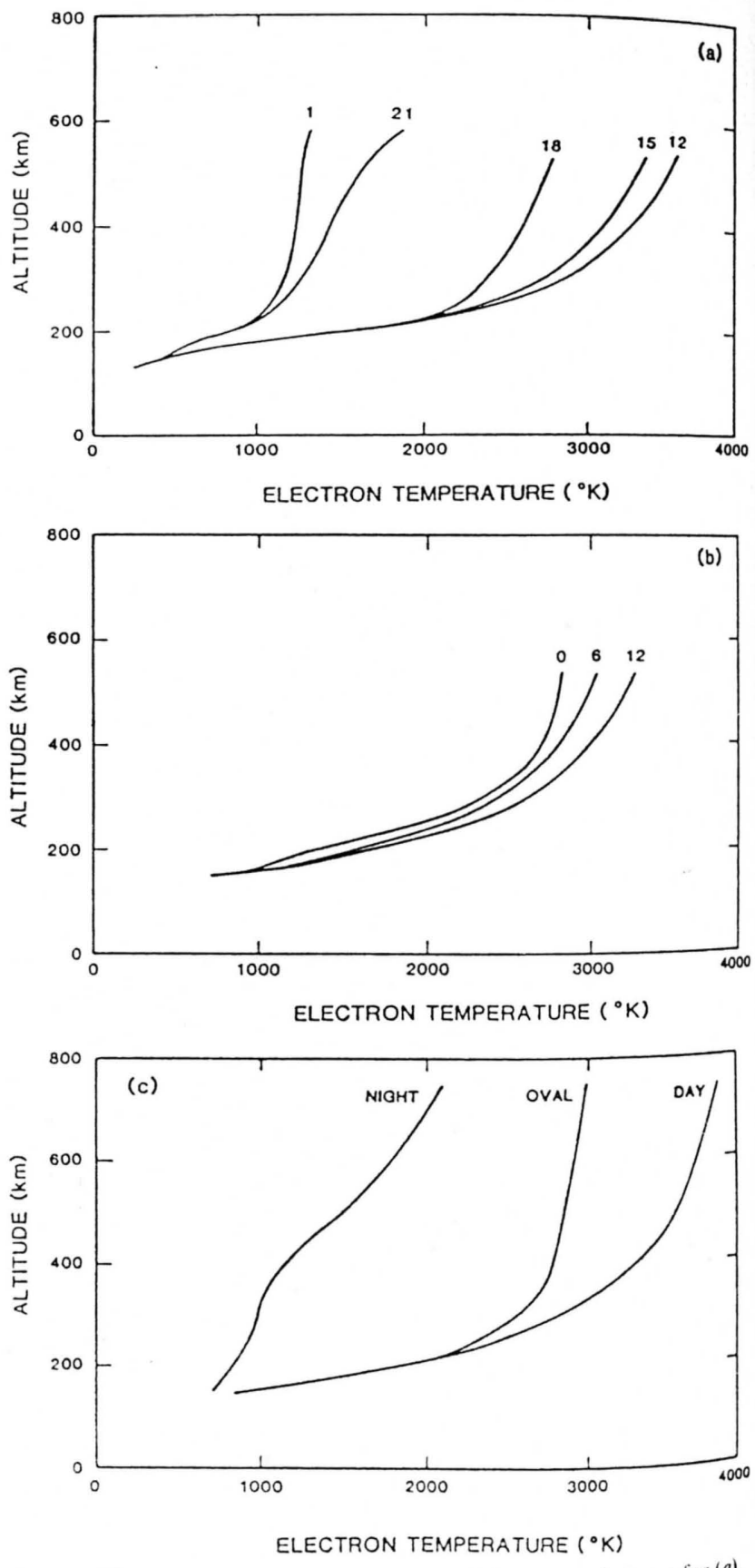

Fig. 8. Electron temperature profiles at different local times for $(a)$ Millst one Hill and $(b) C$ hatanika. The numbers at the top of the profiles give the magnetic local time at which the measurements were made. The electron temperature inputs to the model are plotted in Figure $8 \mathrm{c}$ for the extreme night, the extreme day, and the auroral oval. 


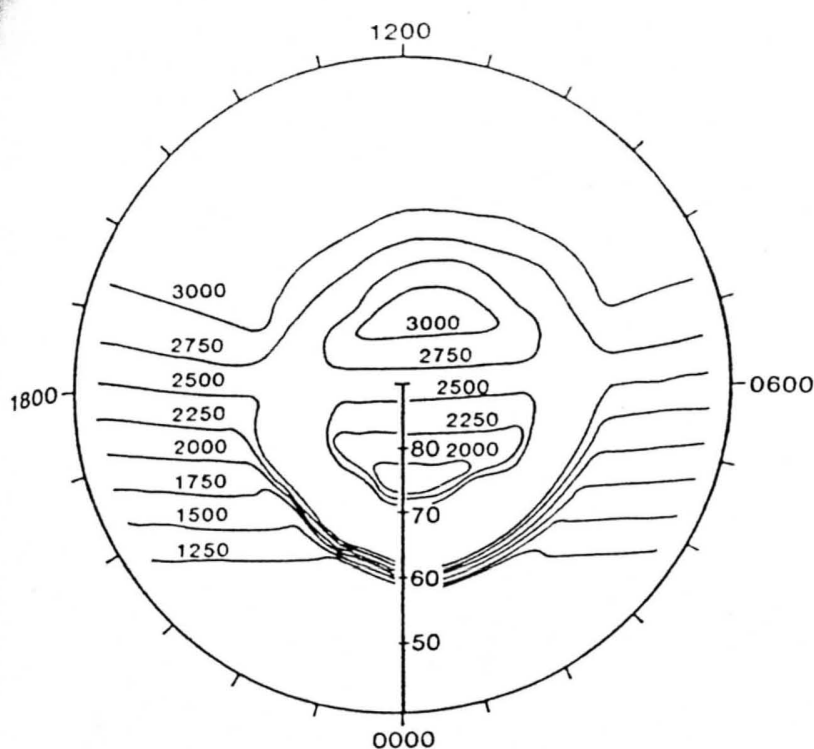

Fig. 9. Contours of electron temperature at an altitude of $350 \mathrm{~km}$ used in the high-latitude model. The contour levels are in degrees Kelvin. Magnetic dipole latitude is indicated on the radial axis and magnetic local time on the outer circle.

\subsection{Electron Temperature}

Another of the input parameters for the high-latitude model is the electron temperature. The ion temperatures are calulated [see Schunk and Sojka, 1982a], but presently the electron temperature is not and must be input to the model. Therefore, the diurnal variation in electron temperature, as measured by Millstone Hill (at $50^{\circ}$ dipole latitude) and Chatanika (at $65^{\circ}$ dipole latitude), was obtained for the days under consideration and is plotted in Figures $8 a$ and $8 b$. This is to be compared with the electron temperature profiles used in our model, which are shown in Figure $8 c$.

Although only three model temperature profiles are shown in Figure $8 c$, the actual electron temperature is varied smoothly from the nighttime to daytime values in regions where the solar zenith angle falls between $70^{\circ}$ and $110^{\circ}$. This can be seen in Figure 9 where contours of electron temperature are plotted at a constant altitude of $350 \mathrm{~km}$, at a universal time of 0500 hours. The transition to the oval temperature occurs whenever the precipitating, electron energy flux exceeds $0.1 \mathrm{erg} \mathrm{cm}^{-2} \mathrm{~s}^{-1}$. Thus, the effect of the a uroral oval is seen as the circular feature between roughly $60^{\circ}$ and $70^{\circ}$ in the figure. Note that the measurements by Chatanika of the electron temperature were made at $65^{\circ}$ and, thus, were taken mostly within the location of our auroral oval. This would lead to the prediction that Chatanika should see little variation in electron temperature as a function of local time, exactly as is shown in Figure $8 b$.

\subsection{Self-Consistency of Input Parameters}

A few comments should be made concerning the coupling between the various input parameters needed by our model. It is well known that several of the input parameters are strongly coupled. For example, the $F$ region electron temperature is coupled to soft precipitation, and the high-latitude neutral wind is coupled to the electric field via ion drag. Also, a correlation has been noted between the location of the high-latitude boundary of the auroral oval and the region demarcating predomi- nantly antisunward flow in the polar cap from east-west convection outside of the polar cap (see Figure 2). In quantifying the input parameters, this correlation and the strong coupling between input parameters were rot "directly" taken into account. We simply fit data measured during the time period of this study to empirical models. Although, at first thought, this may seem to be an oversight, any correlation that exists between the various input parameters will be reflected in the measurements of these parameters and hence will be incorporated in the empirical models.

Another point concerning self-consistency is that the electron densities calculated by our model are coupled to the input parameters. For example, the convection electric field (an input) depends on the conductivity of the ionosphere, which in turn depends on the ionospheric density. This coupling is not "explicitly" taken into account, and hence, our model is not entirely self-consistent in that only a portion of the magnetosphere-ionosphere-thermosphere system is solved. The alternative to solving the entire system simultaneously, taking into account the coupling between the various parts of the system in a self-consistent manner, is to treat the influence of the magnetosphere and the thermosphere on the ionosphere as know inputs, as we have done. If the magnetospheric and thermospheric "input" parameters are measured simultaneously with the ionospheric "output" parameters, the selfconsistency of the entire system will be assured.

\section{Comparison Of Model Calculations AND RADAR OBSERVATIONS}

\subsection{High-Latitude Density Distributions}

The high-latitude model was run with the inputs given in the previous section. The model predicts the density of several ion species as a function of altitude as well as latitude, longitude, and universal time. In this section, the model predictions of electron density are compared with data obtained from the Millstone Hill and Chatanika radars.

There are several ways to present the data obtained by the high-latitude model. One way is to plot the data at a given altitude and at a given universal time. However, since the radars are able to measure only a portion of ionosphere at a given time, they are not able to provide a "snapshot" of the ionosphere. Thus, we mimic this limitation by sampling the data base created by the model in the same way that the radars measure the ionosphere, sampling the data base from a fixed spatial position, with full longitudinal coverage obtained in any given 24-hour period. This allows us to directly compare the results of the model with the data obtained by the radars. This is done for Millstone $\mathrm{Hill}$ in Plate 1 and for Chatanika in Plate 2 at an altitude of $350 \mathrm{~km}$. The data displayed in the left panel in these two plates are the radar data, while the data displayed in the right panel are the model predictions. (Plates 1 and 2 can be found in the separate color section in this issue.)

The model and Millstone both show a fairly uniform electron density of about 5.7 (log scale) from 1100 to $1900 \mathrm{MLT}$. The spot of apparently high electron density near 1300 MLT in the left panel is due to a satellite echo. Similarities are noted in the evening sector as well. Millst one Hill measured a sharp decrease in electron density extending poleward of $65^{\circ}$ near 1900 hours. This decrease in density expands equatorward with increasing local time. In the model, a corresponding decrease beginning at 
about 1800 hours marks the convection reversal between plasma flowing eastward (high-density region) and plasma flowing westward (low-density region).

The convection of the plasma can be seen to be an important process in determining ionospheric densities by comparing the different convection regions (constant in time) shown in Figure 4 with the plasma densities predicted by the model in Plate 1. The trough feature mentioned above is poleward of trajectory 2 (see Figure 4), where the plasma is nearly stagnant. Also note that t rajectory 2 moves equatorward with increasing local time, just as the trough does. This region of decreased density is created by plasma being driven downward as it crosses the polar cap (see Figures 4 and 5), followed by convection westward, rather than a decrease in solar EUV since the furthermost antisunward extent of trajectory 4 is just above the terminator. Foster [1984] has also noted the strong correlation between plasma convection and ionospheric-density features.

In most of the predawn sector (Plate 1) the model and Millstone Hill data show fairly good agreement. There is a region of low density between 2400 and 0400 hours in MLT and centered in dipole latitude about $60^{\circ}$ in both the model and the Millstone Hill data. This trough is principally caused by the effects of vertical drifts. The plasma following trajectory 5 (see Figure 4) goes through the middle of the region of strongest downward drift (see Figure 5), yet it does not travel far enough equatorward after leaving the polar cap to be lifted much by the neutral wind (see Figure 6). The plasma equatorward (at 2400 hours) of trajectory 5 is lifted by the neutral wind and, hence, has a higher density; the plasma poleward of trajectory 5 (trajectory 6 ) enters the auroral oval and, hence, has a higher density. Thus, the deepest portion of the trough is centered around trajectory 5 . Although there are many other processes affecting ionospheric density included in the model (notably effects due to changes in the temperature of the electrons and the ions) the formation of this particular trough is primarily understood in terms of the vertical motion of the plasma.

The plasma density is seen to increase in both the model and Millst one Hill data equatorward of $60^{\circ}$. This points out the fact that vertical motion can in some situations compete with solar maintenance processes since the plasma equatorward of $60^{\circ}$ spends a longer period of time in darkness than plasma at the center of the trough (the terminator is located at about $78^{\circ}$ dipole latitude near magnetic midnight). In the model, this increase in principally caused by a greater lifting of the plasma by meridional winds (see Figure 6).

The effect of auroral precipitation is clearly seen in the model by the increase in plasma density starting at about 0200 hours, poleward of $66^{\circ}$. The effect of auroral precipitation is not as clearly seen in the Millst one Hill data, although there is a slight increase in density from $1.6 \times 10^{5}$ to $2.5 \times 10^{5}$ over a broader latitudinal range (poleward of $62^{\circ}$ ). Apparently, the precipitating flux from our model auroral oval should be lower in value and spread over a wider latitudinal range.

In the dawn sector, the data in both panels show an increase in density to a fairly uniform value as the plasma moves into sunlight, although this happens more quickly in the model. Poleward of $65^{\circ}$ latitude, much of this early increase happens because of the increased ionization due to auroral precipitation; however, equatorward of $65^{\circ}$ this is not the reason.

The model and Chatanika both show (Plate 2) a fairly uniform electron density of about $5 \times 10^{5}$ from 1100 to $1800 \mathrm{LT}$. although again as in Plate 1, predictions from the model peak earlier in time than do the radar data. Again, there is an evening trough which develops near $1700 \mathrm{MLT}$ poleward of $65^{\circ}$ latitude and extends further equatorward with increasing local time. The location of the terminator is at $66^{\circ}$ near magnetic midnight, so most of the ionosphere displayed in Plate 2 is in at least partial sunlight.

In the postmidnight sector, the Chatanika data possibly show the effects of auroral precipitation, although the increased density within the auroral oval is more noticeable in the model predictions in the right-hand side of Plate 2. Again, the predicted densities within the oval are too high and occupy too narrow a band in latitude.

Two features in the Chatanika data are difficult to explain with the model we are using. These two features are the comparatively low-density regions between 0600 and $0800 \mathrm{MLT}$ poleward of $66^{\circ}$ and at about $2000 \mathrm{MLT}$ equatorward of $65^{\circ}$. They appear to be anomalous in that they are surrounded on either side in longitude by regions of relatively higher density. This makes it difficult to explain in terms of plasma convection. However, strong convection at these times could lead to ion heating, which in turn would lead to a decrease in plasma density. In support of this hypothesis, it is noted that these regions correspond to times of substorm activity (starting at 0430 and 1600 UT on June 27) [de la Beaujardiere et al., 1983]. Substorm conditions are evident by the increased convection velocities in Figure $1 a$ during these two times.

A comparison of the left-hand sides of Plates 1 and 2 shows the presence of a distinct trough in the Millstone Hill data but not in the Chatanika data. Although the Chatanika data extend equatorward to only $60^{\circ}$, the Chatanika radar should have still measured the poleward edge of the trough had it been there at the time the radar was probing that part of the ionosphere. By just comparing the two radar measurements, it is difficult to ascertain whether the absence of the trough in the Chatanika data is due to a universal time effect associated with the motion of the terminator, or whether it is due to changing magnetospheric conditions. However, since the same trend is predicted by the model, which contained fixed magnetospheric inputs, it is concluded that this is a UT-terminator effect.

In Plate 3 a similar comparison is made of Chatanika data with model predictions at an altitude of $278 \mathrm{~km}$. (Plate 3 can be found in the separate color section in this issue.) The same features are evident in Plate 3 as are in Plate 2, including the two regions of low density occurring during substorms. This makes it doubtful that the two low-density regions are caused by a downward drift of the plasma, since a downward drift would tend to increase the densities below the $F_{2}$ peak rather than to decrease them.

Again, the modeled auroral oval leads to excessively high ionospheric densities in the model predictions. At this altitude the effects of plasma convection are weaker than at higher altitudes, and chemical reactions dominate. Apparently, we have overestimated auroral precipitation in the model. It is not clear why this is so, as the auroral oval was carefully matched with data from the NOAA 6 satellite. Since the a uroral precipitation was highly variable, we could have overestimated precipitation by fitting the auroral oval to the peaks in the NOAA 6 measurements rather than to the a verage value. Or, if the actual precipitation spectrum was harder than the spectrum for which the model was calibrated, the ionization would be created lower in altitude and would have a less noticeable effect at $F$ region heights. 


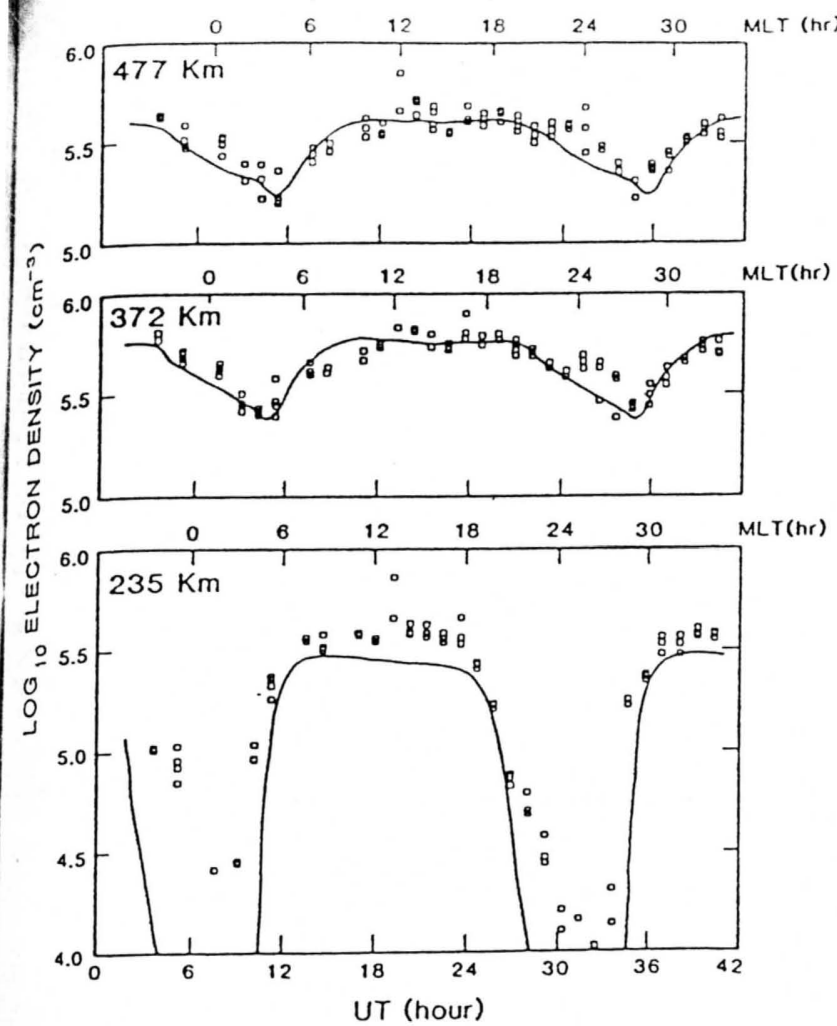

Fig. 10. A comparison of the diurnal variation in electron density measured by the Millstone Hill radar and the variation predicted by the model. The squares represent data obtained by the radar, and the line represents model predictions. Universal time is plotted on the bottom axis and magnetic local time on the top axis. Data were selected at a magnetic latitude of $50^{\circ}\left( \pm 2^{\circ}\right)$, at three different altitudes: $235 \mathrm{~km}, 372$ $\mathrm{km}, 477 \mathrm{~km}( \pm 5 \mathrm{~km})$.

\subsection{Corotating Millstone Hill Density Profiles}

The trajectory of a corotating ionospheric flux tube was followed throughout an entire day. The total ion densities are shown in Figure 10 at three different altitudes. The lines represent the model results, while the squares are data obtained by the Millstone Hill radar making measurements in a westwardly direction. As can be seen in this figure, the model gives remarkably good agreement with the Millstone Hill radar when it is pointing westward, especially at the higher altitudes. Below the $F_{2}$ peak $(235 \mathrm{~m})$ the dayside model values are about $50 \%$ lower than the observed densities. Also, the rate of decrease in plasma density as the plasma moves into darkness is predicted by the model to be greater than is actually the case.

One possible reason for the model values being systematically lower than the measured data at lower altitudes is that the radar measurements are convolved over an extended range along the radar line of sight (48 km for Chatanika and $300 \mathrm{~km}$ for Millstone Hill). Thus, when the plasma density is increasing rapidly with altitude, as it is below the $F_{2}$ peak, the radars will tend to overestimate the density at a given altitude. This is especially critical at night, when the scale height below the $F_{2}$ peak decreases. As this is exactly the trend noted in Figure 10, this explanation appears to be a likely reason for the discrepancy.

Another possible reason for the discrepancy is that substorms could have substantially altered the neutral atmosphere from the mass spectrometer/incoherent scatter(MSIS) model atmosphere. This would have affected the model predictions as well, as the plasma is dominated by chemical reactions below the $F_{2}$ peak.

\subsection{Local Chatanika Density Profiles}

One of the scanning modes for the Chatanika radar allows for particularly good vertical resolution a long the field line directly above the radar site $\left(65^{\circ}\right.$ magnetic latitude). These data are shown in the left-hand panel of Plate 4 as a function of MLT, and the corresponding model results are displayed in the righthand panel. (Plate 4 can be found in the separate color section in this issue.) The highest densities measured by the Chatanika radar are about $6 \times 10^{5}$ at dawn and again at dusk. The same peak value is predicted by the model, although the peak only exists at dawn, the dusk value being about $25 \%$ lower.

Below about $250 \mathrm{~km}$ the model predictions and observations both show fairly constant densities during the daylight hours with a drop in density at night, centered around $2200 \mathrm{MLT}$. The major difference at heights below $250 \mathrm{~km}$ is the layer of ionization measured by the radar centered near $110 \mathrm{~km}$. This ionization layer, due to a uroral precipitation, is somewhat evident in the model predictions, although it is lower by almost an order of magnitude at $2300 \mathrm{MLT}$, coming into closer agreement after magnetic midnight.

Above $250 \mathrm{~km}$ the two data sets have the same general features, although there is a noticeable difference in the height $\left(h_{m} F_{2}\right)$ of the $F$ region peak density as the local time changes. The predicted height of the peak density is relatively constant at about $340 \mathrm{~km}$, while the height measured by Chatanika varies from $300 \mathrm{~km}$ to $400 \mathrm{~km}$. The height $h_{m} F_{2}$ is sensitive to the vertical motion of the ionosphere caused by the neutral wind. The neutral wind data supplied by Chatanika show a large variation, but the overall trend correlates very well with the $h_{m} F_{2}$ values evident in the left panel of Plate 4. In particular, the peak in the neutral wind, which tends to force the ionosphere up magnetic field lines at night, occurs at about 0330 MLT, which is very near to the time when the maximum value of $h_{m} F_{2}$ is reached. We could have incorporated this trend of the neutral wind into our model, but it is unclear from this limited set of data whether this is a local effect or a temporal effect, whether it might possibly be due to an upwelling of the neutral atmosphere caused by auroral heating or due to an entirely different mechanism.

\section{Additional Model Coverage}

The format used in presenting the data in Plates 1 and 2 is somewhat misleading in that it implies full longitudinal coverage by the radars. In a way the radars do provide full longitudinal coverage, but only once in any given 24 -hour period. This limitation makes it difficult to distinguish between temporal effects due to substorms and persistent features at a given longitudinal location. Another limitation of the radar coverage in this study is that the field of view of the radars covers only a limited latitudinal band and does not allow the polar cap to be studied. However, these limitations can, in a sense, be overcome by judicious use of the high-latitude model. Through use of the radars and from data obtained from other sources, the inputs to the model can be established and verified, as has been done in the previous two sections. Then, the model results can be examined in reference frames unavailable to the radars. This is done in this section.

Electron densities predicted by the model are displayed in 
Plate 5 at three different altitudes: 250,350 , and $785 \mathrm{~km}$. (Plate 5 can be found in the separate color section in this issue.) The densities are shown at two distinct universal times of 0500 and 1700 hours at each respective altitude. In the middle left panel the same plasma trajectories plotted in Figure 4 are superimposed on the density plot. Notice how well the various regions of ionospheric density correlate with the differing regions of convection. For instance, the "tongue of ionization" within the polar cap is confined to the region of antisunward flow, while the two arms of low density on either side of the tongue of ionization lie within the region of sunward flow of the dawn and dusk convection cells. These two low-density regions extend sunward to nearly 1200 in the postnoon sector and to 0900 in the prenoon sector. Latitudinally, these low-density arms are located poleward of $70^{\circ}$ on the dayside, and hence, are just outside of the radar's field of view, as can be seen in a comparison of Plates 1, 2, 3, and 5. However, substorms might temporarily move these cells equatorward, moving the regions of low density into the radar's field of view. This is a possible explanation for the two regions of "anomalously" low density mentioned in conjunction with Plates 2 and 3 in section 4.1.

The middle panel of Plate 5 can be compared with Plates 1 and 2 , which contain densities sampled at the same altitude, at a fixed location over a 24-hour period. Not surprisingly, similar features are evident in Plates 1 (right panel) and 5 (middle left panel), since Millst one Hill was near magnetic midnight at 0500 UT. Thus, the nighttime features are similar, and the daytime features are similar as well since most of the polar ionosphere is sunlit on June 27. However, note the distinct differences between the two middle panels of Plate 5, primarily due to a change in the location of the terminator (UT effect).

The effect of the movement of the terminator in the MLT reference frame can be clearly seen by comparing the lower left and lower right panels in Plate 5. The movement of the terminator (in the magnetic reference frame) causes a distinct dependence of the ionosphere on universal time. The terminator lies along the line separating the region of densities below $7 \times 10^{4}$ in the lower right panel. Notice, in the right-hand panels of Plate 5 , how the line of decreased densities near the teminator appears to twist, increasingly eastward, with increasing altitude. This takes place because the time scale for the decay of plasma density is much greater at higher altitudes, and hence, the high densities produced in sunlight are convected further eastward before decaying in darkness. The upper two panels also show more clearly the effects of the convection pattern, as evidenced by the two-cell nature of the density patterns at high altitudes. In contrast, at $250 \mathrm{~km}$, photochemical time constants are short, and the plasma density is correlated more closely with solar radiation than it is with the plasma convection pattern.

\section{Summary And Conclusions}

The MITHRAS data set provides the opportunity to check the validity of many of the assumptions that enter into our high-latitude ionospheric model. For instance, the extended coverage of multiple radars is especially important because, at a given UT, it provides information separated in local time. Thus, not only can the required inputs to the model be more accurately ascertained, but such phenomena as the UT dependence of the ionosphere can be noted and checked. We view an interaction and dialog between those modeling the ionosphere and those making measurements of the ionosphere to be extremely important. From a modeler's point of view, the radar data are necessary to check the basic assumptions of the model. But a model of the ionosphere is equally important to those making measurements, as it provides a paradigm against which to interpret the mass of data collected and to plan for future experiments.

In this work we have made an effort to provide reliable inputs to the model by carefully matching statistical models of the required input parameters with data obtained from three different radar sites and from the NOAA 6 satellite. This is the first study where this has been done with our high-latitude model. Other studies, for instance Sojka et al. [1983], were parametric studies where the model inputs were varied over a range of values.

The four main inputs to the model are the convection electric field, the thermospheric wind, the auroral-electron energy flux, and the electron temperature distribution. Of the four inputs, the convection electric field was covered the best, since simultaneous data from three radar sites were available for this study. With modifications, the Volland [1978] statistical model provided a quantitative description of the convection electric field that agreed substantially with all three radar sites. It is notable that all three radars measured approximately the same convection pattern, including a westward rotation of 1.75 hours from midnight of the region where the electric field reversal occurs. The only apparent discrepancies between the statistical model and the radar measurements were at times of substorm activity. The excellent agreement between the modified Volland model and the three radars suggests that the radar measurements of the convection electric field are describable by a statistical model. Although this statement may at first appear obvious, it is not at all certain that a statistical representation (obtained from data gathered over months of time) can adequately represent conditions pertaining at a given time.

Likewise, adequate information concerning the electron temperature in the high-latitude ionosphere was available from the Chatanika and Millstone Hill radars. However, data pertaining to thermospheric winds were limited and had a relatively large degree of uncertainty associated with them. The ionosphere is sensitive to these winds; for instance, a difference of $60 \mathrm{~m} / \mathrm{s}$ in the neutral wind can change dayside densities by $25 \%$ at the $F_{2}$ peak and above. In comparison, the wind data were uncertain by about $30 \mathrm{~m} / \mathrm{s}$ in the daylight regions. On the nightside, where the wind data varied by as much as $100 \mathrm{~m} / \mathrm{s}$ over a half-hour time period, the ionosphere is even more sensitive to thermospheric winds.

The measurements of auroral precipitation were also limited. The NOAA 6 satellite provided good coverage of dayside precipitation, but no coverage on the nightside in the northern hemisphere. Thus, NOAA 6 coverage of the nightside in the southern hemisphere was assumed to represent conditions in the northern hemisphere as well. The statistical model of Spiro at al. [1982] was modified to represent the measurements of the NOAA 6 satellite, but the spatial orientation of the model was uncertain by $2^{\circ}$ to $3^{\circ}$ in latitude and even more in longitude. Also, the data were highly variable in time and, hence, it is probably more appropriate to modify the statistical model to fit a temporal average of the data, rather than to fit the peak values as was done in this study. In contrast to the model of the convection electric field, it is uncertain whether a statistical model of auroral precipitation is adequate for modeling the high-latitude ionosphere-primarily because the precipitation is temporally variable and the ionosphere rapidly responds to these variations. 
In spite of the somewhat limited input data, the densities predicted by the high-latitude model (section 4 ) are remarkably similar to those measured by the radars. The comparisons of data with predictions at 350 and $278 \mathrm{~km}$ were good in regions where sunlight dominates production, implying that estimates of winds, temperatures, neutral composition, reaction rates, etc., are reliable there. In regions of decreasing sunlight, the predicted and observed trough densities and locations were similar. Particularly notable is the conjunction between the location of the troughs and the convection pattern. Also, the formation of the mid-latitude trough had a distinct UT dependence which was evident in both the radar data and the model predictions.

The agreement in the diurnal variation of electron density is remarkable (especially at the two higher altitudes, Figure 10) at $50^{\circ}$ magnetic latitude. However, a similar comparison at $65^{\circ}$ (Plate 4) is not as good. In particular, it is apparent that the $h_{m} F_{2}$ variation is not well predicted. This might be due to several processes, including those associated with auroral precipitation, neutral winds, or the convection electric field. Without more precise input data, it is difficult to more fully understand the discrepancy in $h_{m} F_{2}$. The discrepancies could have been substantially decreased by varying the neutral wind within the limits of the uncertainties of the radar measurements, but the same could be said of many of the other input parameters. Other areas of disagreement were noted in the region of the auroral oval and at a portion of the times during which substorms occurred.

A point might be made about studies comparing model predictions with data such as this one. In a scientific sense, complete agreement between the model and measurement is somewhat a nulY result, because it implies that the topic is completely understood and nothing new is to be learned. Discrepancies between the model and data, on the other hand, imply that something is not well understood and that there is scientific benefit to be gained by further refinement of the model or in a reinterpretation of the data. In this light, the model appears to be complete in terms of large-scale ionospheric processes, such as solar production of ionization and the subsequent chemical reactions and transport-at least for summer seasonal conditions, moderate activity, and solar maximum - as the predicted densities are mostly within $25 \%$ of the measurements. There are areas of disagreement, such as within the auroral oval and during periods of substorm activity. However, further study, with more definitive inputs, is needed before the cause, or causes, of these differences can be ascertained.

Acknow'ledgments. We thank the many SRI and MIT Haystack personnel who have helped make this research possible. In particular, we appreciate the considerable efforts of Caroi Leger. The SRI portion of this resea rch was supported by AFOSR contracts F49620-81-C-0042 and F49620-83-K-0005, the Utah State University portion by AFOSR contract AFOSR-84-0029 and NOAA contract ATM81-19477, and the Millstone Hill portion by AFOSR-83-0002.

The Editor thanks M. J. Baron and R. A. Greenwald for their assistance in evaluating this paper.

\section{REFERENCES}

Baron, M. J., The Chatanika Radar System, in Radar Probing of the Auroral Plasma, edited by A. Brekke, pp. 103-141, Universitetsforlaget, Tromso, Norway, 1977.

Brinton, H. C., J. M. Grebowsky, and L. H. Brace, The high-latitude winter $F$ region at $300 \mathrm{~km}$ : Thermal plasma observations from AE-C, J. Geophys. Res., 83, 4767-4776, 1978.

de la Beaujardiere, O., J. Holt, and E. Nielsen, Early MITHRAS results: The electric field response to substorms, Radio Sci., 18. $981-987,1983$

de la Beaujardiere, O.. V. B. Wickwar, M. J. Baron, J. Holt, R. M. Wand, W. L. Oliver, P. Bauer, M. Blanc, C. Senior, D. Alcayde, G. Caudal, J. Foster, E. Nielsen, and R. Heelis, MITHRAS: A brief description, Radio Sci., 19, 665-673, 1984

Foster, J. C., Ionospheric signatures of magnetospheric convection, J. Geophys. Res., 89, 855-865, 1984.

Foster, J. C., J. R. Doupnik, and G. S. Stiles, Large scale patterns of auroral ionospheric convection observed with the Chatanika radar. J. Geophys. Res., 86, 11357-11371, 1981.

Greenwald, R. A., W. Weiss, E. Nielsen, and N. R. Thompson, ST ARE: A new auroral backscatter experiment in northern Scandinavia, Radio Sci., 13, 1021-1039, 1978.

Heelis, R. A., J. K. Lowell, and R. W. Spiro, A model of the highlatitude ionospheric convection pattern, J. Geophys. Res., 87, 6339-6345, 1982.

Holt, J. M., R. H. Wand, and J. V. Evans, Millstone Hill measurements on 26 February 1979 during the solar eclipse and formation of a midday F-region trough, J. Atmos Terr. Phys., 46, 251-264, 1984.

IAGA Division 1, Working Group I, International geomagnetic reference fields: DGRF 1965, DGRF 1970, DGRF 1975, and IGR F 1980, Eos Trans. AGU, 62,1169, 1981

Jorgensen, T. S., E. Friis-Christensen, V. B. Wickwar, J. D. Kelly, C. R. Clauer, and P. M. Banks, On the reversal from "sunward" to "antisunward "plasma convection in the dayside high latitude ionosphere, Geophys. Res. Lett., 11, 887-890, 1984.

Kofman, W., and V. B. Wickwar, Plasma line measurements at Chatanika with high-speed correlator and filter bank, J. Geophys. Res., 85 , 2998-3012, 1980.

Mead, G. D., International geomagnetic reference field 1965.0 in dipole coordinates, J. Geophys. Res., 75, 4372-4374, 1970.

Nielsen, E., and K. Schlegel, A comparison of STARE and EISCAT electron drift velocity measurements, J. Geophys. Res., 88, 5745-5750, 1983.

Oliver, W. L., J. M. Holt, R. H. Wand, and J. V. Evans, Millstone Hill incoherent scatter observations of auroral convection over $60^{\circ}<\Lambda<$ $75^{\circ}, 3$, Average patterns versus $K p, J$. Geophys. Res., 88, 5505-5516, 1983.

Schunk, R. W., and W. J. Raitt, Atomic nitrogen and oxygen ions in the daytime high-latitude $F$ region, J. Geophys. Res., 85, 1255-1272, 1980.

Schunk, R. W., and J. J. Sojka, Ion temperature variations in the daytime high-latitude $F$ region, $J$. Geophys. Res., 87, 5169-5183, $1982 a$

Schunk, R. W., and J. J. Sojka, Ionospheric hot spot at high latitudes, Geophys. Res. Lett., 9, 1045-1048, 1982 b.

Sojka, J. J., J. C. Foster, W. J. Raitt, R. W. Schunk, and J. R. Doupnik, High-latitude convection: Comparison of a simple model with incoherent scatter observations, J. Geophys. Res., 85, 703-709, 1980.

Sojka, J. J., W. J. Raitt, and R. W. Schunk, A theoretical study of the high-latitude winter $F$ region at solar minimum for low magnetic activity, J. Geophys. Res., 86, 609-621, $1981 a$.

Sojka, J. J., W. J. Raitt, and R. W. Schunk, Theoretical predictions for ion composition in the high-latitude winter $F$ region for solar minimum and low magnetic activity, J. Geophys. Res., 86, 2206-2216, $1981 b$.

Sojka, J. J., W. J. Raitt, and R. W. Schunk, Plasma density features associated with strong convection in the winter high-latitude $F$ region, J. Geophys. Res., 86, 6908-6916, $1981 c$.

Sojka, J. J., R. W. Schunk and W. J. Raitt, Seasonal variations of the high-latitude $F$ region for strong convection, J. Geophys. Res., 87, 187-198, 1982a.

Sojka, J. J., W. J. Raitt, R. W. Schunk, F. J. Rich, and R. C. Sagalyn, Observations of the diurnal dependence of the high-latitude $F$ region ion density by DMSP satellites, J. Geophys. Res., 87, 1711-1718, $1982 b$.

Sojka, J. J., R. W. Schunk, J. V. Evans, J. M. Holt, and R. H. Wand, Comparison of model high-latitude electron densities with Millstone Hill observations, J. Geophys. Res., 88, 7783-7793, 1983.

Spiro, R. W., P. H. Reiff, and L. J. Maher, Precipitating electron energy flux and auroral zone conductances-An empirical model, $J$. Geophys. Res., 87, 8215-8227, 1982.

Volland, H., A model of the magnetospheric electric convection field, $J$. Geophys. Res., 83, 2695-2699, 1978.

Wickwar, V. B., M. J. Baron, and R. D. Sears, Auroral energy input 
from energetic electrons and Joule heating at Chatanika, J. Geophys. Res., 80, 4364-4367, 1975.

Wickwar, V. B., J. D. Kelly, O. de la Beaujardiere, C. A. Leger, F. Steenstrup, and C. H. Dawson, Sondrestrom overview, Geophys. Res. Lett., 11, 883-886, 1984a.

Wickwar, V. B., J. W. Meriwether, Jr., P. B. Hays, and A. F. Nagy, The meridional thermospheric neutral wind measured by radar and optical techniques in the auroral region, J. Geophys. Res., 89, $10,987-10,998,1984 b$.

O. de la Beaujardiere and V. B Wickwar, SRI International, 333 Ravenswood Avenue, Menlo Park, CA 94025.
D. S. Evans, National Center for Atmospheric Research, Bon CO 80303.

J. Foster and J. Holt, Haystack Observatory, Westford, MA E. Nielsen, Max-Planck-Institut für Aeronomie, 341 $\mathrm{K}_{\text {A }} 0188$ Lindau, Federal Republic of Germany.

C. E. Rasmussen, R. W. Schunk, and J. J. Sojka, Centerfor A pheric and Space Sciences, Utah State University, Logan, Atmos 3400, (80 I) 750-2961, TELEX 3789426.

(Received February 21, 1985; revised June 10, 1985; accepted June 11, 1985.) 